\title{
Psychosocial work exposures and suicide ideation: a study of multiple exposures using the French national working conditions survey
}

\author{
Isabelle Niedhammer ${ }^{1 *}$ (D, Maryline Bèque ${ }^{2}$, Jean-François Chastang ${ }^{1}$ and Sandrine Bertrais ${ }^{1}$
}

\begin{abstract}
Background: Our study aimed to explore the associations between psychosocial work exposures, as well as other occupational exposures, and suicide ideation in the French national working population. An additional objective was to study the cumulative role of occupational exposures in this outcome.

Methods: The study was based on a nationally representative sample of the French working population of 20,430 employees, 8579 men and 11,851 women (2016 French national Working Conditions survey). Occupational exposures included 21 psychosocial work factors, 4 factors related to working time/hours and 4 factors related to the physical work environment. Suicide ideation within the last 12 months was the outcome. The associations between exposures and outcome were studied using weighted logistic regression models adjusted for covariates.

Results: The 12-month prevalence of suicide ideation was 5.2\% among men and 5.7\% among women. Among the occupational exposures, psychosocial work factors were found to be associated with suicide ideation: quantitative and cognitive demands, low influence and possibilities for development, low meaning at work, low sense of community, role conflict, job insecurity, temporary employment, changes at work, and internal violence. Some rare differences in these associations were observed between genders. Linear associations were observed between the number of psychosocial work exposures and suicide ideation.

Conclusions: Psychosocial work factors were found to play a major role in suicide ideation, and their effects were cumulative on this outcome. More research on multiple and cumulative exposures and suicide ideation and more prevention towards the psychosocial work environment are needed.
\end{abstract}

Keywords: Suicide ideation, Psychosocial work factors, Job stress, Working conditions, Occupational exposures

\section{Background}

Suicide has become a major issue in occupational health, as although the rate of suicide is higher among unemployed and economically inactive people than among

\footnotetext{
* Correspondence: isabelle.niedhammer@inserm.fr

${ }^{1}$ INSERM, Univ Angers, Univ Rennes, EHESP, Irset (Institut de recherche en santé, environnement et travail) - UMR_S 1085, ESTER Team, 28 rue Roger Amsler, CS 74521, 49045, Angers, France

Full list of author information is available at the end of the article
}

employed people, the total number of suicides is higher in the working population than in the non-working population [1]. Furthermore, a substantial body of the literature was published on the associations between occupation and suicide, and showed that some occupations were at higher risk of suicide than others [2, 3]. Nevertheless, the literature appears scarce on the factors that may explain the differences in suicide risk between occupations. 
Psychosocial work factors may have detrimental effects on health, particularly on mental health. Literature reviews and meta-analyses underlined the associations between psychosocial work factors and various mental health outcomes, especially those related to depression [4-8]. It is thus legitimate to question whether psychosocial work factors may have effects on suicide. To date, two systematic literature reviews were performed, the first one on the association between workplace bullying and suicide ideation [9], and the second one on the associations between the other psychosocial work factors and suicidality [10].

The first review [9] by Leach et al., published in 2017, showed an association between workplace bullying and suicide ideation that was found in 8 studies among the 12 included studies. The second review [10], more comprehensive, that used a meta-analysis, by Milner et al., published in 2018, found that the studied psychosocial work factors were associated with suicide ideation among the 14 included studies. The factors from the job strain model, the most recognized and used theoretical model of job stress, were significantly associated with suicide ideation: high job demands, low job control, job strain (the combination of high demands and low control), and low social support. Two other factors, less studied, were also observed as risk factors: effort-reward imbalance and job insecurity. There was also one included study that reported a significant association between role conflict and suicide ideation. Nevertheless, the authors of these two reviews $[9,10]$ concluded to a lack of high-quality studies and the need for more studies in this area.

Our study is thus a contribution to the literature on the topic of psychosocial work factors in association with suicide ideation. Contrarily to previous studies, it had the advantage to overcome some previous limitations: indeed, we used a large nationally representative sample of the working population and not a sample related to a specific occupation/work sector, we studied both men and women, we explored a large range of psychosocial work factors and not a limited number of factors, and, above all, we examined multiple exposure to these factors, which has never been done to date.

The objectives of this study were to explore the associations of psychosocial work factors, as well as other occupational exposures, with suicide ideation, and also to assess the effects of multiple exposure to these factors.

\section{Methods}

The study relied on the data of the last version of the French national Working Conditions survey performed by DARES (Direction de l'Animation de la Recherche, des Études et des Statistiques) of the French Ministry of Labour in 2016. It was based on a nationally representative sample of the working population aged 15 or more. This sample was selected randomly using a two-stage sampling design, with two successive selections of households and workers (if more than one worker in the household). Data were collected using both a face-to-face interview and a self-administered questionnaire, that was used to collect items on more sensitive issues (suicide ideation, social support outside work, life events, and psychosocial work factors).

Suicide ideation was the outcome and was measured using one item related to suicide thoughts within the last 12 months. The item was the following: 'Within the last 12 months, have you thought about suicide?', that was used in another French national survey, in the general population, the Health Barometer [11].

Occupational factors included 4 groups of factors:

- 21 psychosocial work factors, that were assessed using 79 items, inspired from various concepts including those of the COPSOQ questionnaire (Copenhagen Psychosocial Questionnaire), and grouped into 5 topics:

1. Demands at work: quantitative demands (7 items), cognitive demands (3 items), emotional demands (2 items), demands for hiding emotions (2 items).

2. Work organization and job content: influence at work (6 items), degree of freedom (3 items), possibilities for development ( 5 items), meaning of work (3 items).

3. Interpersonal relations and leadership: social support from supervisors and colleagues (7 items), sense of community (3 items), quality of leadership (5 items), predictability ( 2 items), role clarity (2 items), role conflict (9 items).

4. Work-individual interface: job satisfaction (3 items), work-family conflict (2 items), job insecurity (2 items), changes at work (2 items), temporary employment (1 item).

5. Workplace violence: internal violence at work (i.e. from colleagues, supervisors, etc.) (6 items), external violence at work (i.e. from the public, patients, clients, customers, etc.) (4 items).

The score for each factor was calculated from the sum of the items and dichotomized at the median of the distribution in the total sample, and these binary variables were summed up to construct multiple exposure for each topic and for all psychosocial work factors together.

- 4 working time/hours factors: long working hours (1 item: working more than $48 \mathrm{~h}$ per week, following 
the European directive on working time), night work ( 1 item: working between midnight and 5 am at least 50 nights a year), shift work (1 item, working on alternating/rotating shifts), and unsocial work days (1 item, working on Saturday or Sunday at least 40 times a year).

- 4 physical work factors: biomechanical exposure (7 items: long-term exposure to standing, difficult or tiring position, walking, heavy loads, painful or tiring movements, vibrations, repetitive tasks), exposure to fumes or dust (1 item), exposure to toxic and dangerous products ( 1 item), and exposure to noise (1 item).

Multiple exposure to working time/hours factors and to physical work factors were also constructed.

The following covariates were taken into account: age, marital status (1 item: living with or without a partner), social support outside work ( 2 items: having someone to rely on to discuss personal issues or take a difficult decision, and need more help than help received), life events before the age of 18 and within the last 3 years (among the following items: serious health problems of oneself or close family member, death of close family member, family conflict, and exposure to violence), occupation and economic activity of the company.

The differences between men and women were explored, and following Doyal's definition of gender [12], the term 'gender' was used instead of 'sex' as these differences may be related to biological but also social aspects. Consequently, all analyses were done for men and women separately.

The statistical analyses were performed using weighted data in order to take non-response and marginal calibration into account. Firstly, comparison was done between genders for all studied variables using the Rao-Scott Chi-2 test. The prevalence of suicide ideation was also compared between groups using the same test. Secondly, weighted logistic regression models were used to study the associations between occupational factors and suicide ideation. Three types of model were performed: (1) the first one explored the crude association between each occupational factor and suicide ideation (unadjusted models), (2) the second one additionally adjusted for the forementioned covariates (adjusted models), and (3) the third one explored the association between multiple exposure and suicide ideation with adjustment for covariates. Trend tests were performed for this last model. Sensitivity analyses explored the robustness of the results: (1) with additional adjustment for full/part time work, public/private sector, company size, and chronic disease, and (2) with additional adjustment for working time/hours and physical work factors in the study of multiple exposure to psychosocial work factors.
Statistical gender-related interactions were also tested among the total sample in the models adjusted for covariates to explore potential differences in the exposureoutcome associations between genders and determine their statistical significance.

We used SAS software to perform all statistical analyses.

\section{Results}

The rates of participation to the face-to-face interview (74\%) and of response to the self-administered questionnaire (94\%) were both high. Among the 27,610 participants, 20,430 people were employees, aged 15-65, working at the time of the survey, and responded to the self-administered questionnaire. Thus, the study sample included 20,430 employees, 8579 men and 11,851 women. The description of the sample is presented in Table 1 for the covariates. Significant statistical differences between genders were observed for all covariates except age. Women were more likely to live alone, to have low social support outside work, to report life events, and to work as clerks/service workers and associate professionals/technicians, and to work in the services than men. Significant statistical differences in the prevalence of exposure to occupational factors were also found between genders (not showed). Women were more likely to be exposed to most psychosocial work factors (emotional demands, demands for hiding emotions, low influence, low degree of freedom, low possibilities for development, low job satisfaction, external violence, and job insecurity) than men. Women were also more likely to be exposed to unsocial work days than men. In contrast, men were more likely to be exposed to low meaning of work, role conflict, low predictability, as well as to long working hours, night work, and shift work, and to all physical work exposures than women.

The prevalence of suicide ideation was $5.2 \%$ for men and $5.7 \%$ for women, without any statistical difference between genders. The prevalence of suicide ideation according to covariates is presented in Table 1. This prevalence increased among people living alone, with low social support outside work and life events. There was no statistical difference between age groups, occupations and economic activities of the company.

Table 2 presents the associations between each occupational factor and suicide ideation among men. The associations were significant for all psychosocial work factors before adjustment for covariates except for cognitive demands, degree of freedom, predictability, and temporary employment. After adjustment for covariates, the number of significant associations was lower, but the associations remained significant for quantitative demands, low possibilities for development, low meaning, 
Table 1 Description of the study sample and prevalence of suicide ideation according to covariates

\begin{tabular}{|c|c|c|c|c|c|c|c|c|}
\hline & \multicolumn{4}{|l|}{ Men } & \multicolumn{4}{|l|}{ Women } \\
\hline & \multirow[b]{2}{*}{$\mathrm{n}$} & \multirow[b]{2}{*}{$\%^{b}$} & \multicolumn{2}{|c|}{ Suicide ideation $^{a}$} & \multirow[b]{2}{*}{$n$} & \multirow[b]{2}{*}{$\%^{b}$} & \multicolumn{2}{|c|}{ Suicide ideation $^{a}$} \\
\hline & & & $\%^{\mathrm{b}}$ & $p$-value ${ }^{c}$ & & & $\%^{\mathrm{b}}$ & $p$-value ${ }^{c}$ \\
\hline All & 8579 & - & 5.2 & & 11,851 & - & 5.7 & \\
\hline Age (years) & & & & 0.128 & & & & 0.360 \\
\hline$<30$ & 1020 & 19.0 & 4.4 & & 1283 & 18.1 & 4.7 & \\
\hline $30-39$ & 1864 & 25.5 & 3.7 & & 2473 & 23.6 & 4.7 & \\
\hline $40-49$ & 2799 & 28.6 & 6.9 & & 3820 & 28.1 & 6.0 & \\
\hline$\geq 50$ & 2896 & 26.9 & 5.4 & & 4275 & 30.2 & 6.8 & \\
\hline Marital status & & & & 0.002 & & & & 0.015 \\
\hline Living with a partner & 6827 & 76.2 & 4.3 & & 8849 & 72.6 & 5.0 & \\
\hline Alone & 1752 & 23.8 & 8.0 & & 3001 & 27.4 & 7.7 & \\
\hline Social support outside work & & & & $<0.001$ & & & & $<0.001$ \\
\hline Yes and don't need more help & 6924 & 81.7 & 3.7 & & 8939 & 78.5 & 3.0 & \\
\hline No and don't need more help & 340 & 4.2 & 8.5 & & 353 & 2.9 & 9.7 & \\
\hline Yes but need more help & 1006 & 12.0 & 12.0 & & 1952 & 15.3 & 15.0 & \\
\hline No and need more help & 191 & 2.0 & 16.4 & & 432 & 3.3 & 23.7 & \\
\hline Life event(s) during childhood & & & & $<0.001$ & & & & $<0.001$ \\
\hline None & 4154 & 48.1 & 2.5 & & 4608 & 38.5 & 2.9 & \\
\hline 1 & 2462 & 28.4 & 4.7 & & 3556 & 30.1 & 3.2 & \\
\hline$\geq 2$ & 1926 & 23.6 & 11.3 & & 3644 & 31.3 & 11.6 & \\
\hline Life event(s) within the last 3 years & & & & $<0.001$ & & & & $<0.001$ \\
\hline None & 4675 & 56.4 & 3.0 & & 4854 & 42.6 & 2.1 & \\
\hline 1 & 2588 & 29.4 & 5.3 & & 3945 & 32.1 & 5.3 & \\
\hline$\geq 2$ & 1286 & 14.2 & 13.6 & & 3012 & 25.3 & 12.3 & \\
\hline Occupation & & & & 0.686 & & & & 0.725 \\
\hline Managers, professionals & 2025 & 22.4 & 5.1 & & 1691 & 14.9 & 4.9 & \\
\hline Associate professionals, technicians & 2402 & 25.9 & 4.4 & & 3978 & 27.9 & 5.2 & \\
\hline Clerks, service workers & 1397 & 14.4 & 6.1 & & 5357 & 48.3 & 6.1 & \\
\hline Blue-collar workers & 2681 & 37.3 & 5.5 & & 751 & 8.9 & 6.6 & \\
\hline Economic activity & & & & 0.271 & & & & 0.788 \\
\hline Services & 5993 & 66.2 & 5.6 & & 10,866 & 90.1 & 5.7 & \\
\hline Others & 2579 & 33.8 & 4.5 & & 979 & 9.9 & 6.1 & \\
\hline
\end{tabular}

${ }^{a}$ Data on suicide ideation within the last 12 months were available for 8543 men and 11,795 women

beighted percentages

${ }^{c} p$-value for the comparison of the weighted prevalence of suicide ideation according to covariates (Rao-Scott Chi-square test)

low sense of community, low job satisfaction, job insecurity, temporary employment, and internal violence.

Table 3 presents the associations between each occupational factor and suicide ideation among women. Before adjustment for covariates, almost all psychosocial work factors were significantly associated with suicide ideation, except possibilities for development, predictability, work-family conflict, and temporary employment. After adjustment for covariates, the number of significant associations was reduced, but we observed that exposure to quantitative demands, cognitive demands, low influence, low meaning, role conflict, changes at work, and internal violence were risk factors of suicide ideation.

In the analyses of the total sample of men and women, two significant gender-related interaction terms were found and showed that the association between cognitive demands and suicide ideation was significant among women and not among men $(p=0.001)$, and that the association between job insecurity and suicide ideation was significant among men and not among women $(p=$ $0.040)$. 
Table 2 Associations of occupational exposures with suicide ideation in men. Results from weighted logistic regression analyses (each occupational factor studied separately)

\begin{tabular}{|c|c|c|c|c|c|c|c|c|}
\hline \multirow[t]{2}{*}{$\operatorname{Men}(N=7781)^{a}$} & \multicolumn{4}{|c|}{ Unadjusted } & \multicolumn{4}{|c|}{ Adjusted for covariates ${ }^{c}$} \\
\hline & OR & \multicolumn{2}{|l|}{$95 \% \mathrm{Cl}$} & $p$-value & OR & \multicolumn{2}{|l|}{$95 \% \mathrm{Cl}$} & $p$-value \\
\hline \multicolumn{9}{|l|}{ Psychosocial work factors ${ }^{b}$} \\
\hline \multicolumn{9}{|l|}{ Demands at work } \\
\hline High quantitative demands & 2.00 & 1.32 & 3.03 & 0.001 & 1.74 & 1.10 & 2.76 & 0.018 \\
\hline High cognitive demands & 0.90 & 0.61 & 1.33 & 0.595 & 0.79 & 0.52 & 1.22 & 0.288 \\
\hline High emotional demands & 1.59 & 1.06 & 2.38 & 0.024 & 1.29 & 0.81 & 2.07 & 0.283 \\
\hline High demands for hiding emotions & 2.51 & 1.66 & 3.79 & $<0.001$ & 1.59 & 0.97 & 2.58 & 0.064 \\
\hline \multicolumn{9}{|l|}{ Work organization and job content } \\
\hline Low influence & 1.54 & 1.03 & 2.30 & 0.036 & 1.43 & 0.94 & 2.17 & 0.091 \\
\hline Low degree of freedom & 1.33 & 0.89 & 2.00 & 0.168 & 1.05 & 0.69 & 1.59 & 0.827 \\
\hline Low possibilities for development & 2.41 & 1.58 & 3.67 & $<0.001$ & 1.98 & 1.20 & 3.26 & 0.007 \\
\hline Low meaning of work & 2.29 & 1.46 & 3.59 & $<0.001$ & 1.85 & 1.13 & 3.03 & 0.015 \\
\hline \multicolumn{9}{|l|}{ Interpersonal relations and leadership } \\
\hline Low predictability & 0.88 & 0.57 & 1.34 & 0.542 & 0.85 & 0.54 & 1.34 & 0.486 \\
\hline Low role clarity & 1.62 & 1.08 & 2.42 & 0.019 & 1.34 & 0.86 & 2.07 & 0.194 \\
\hline High role conflict & 1.84 & 1.16 & 2.91 & 0.009 & 1.43 & 0.90 & 2.26 & 0.133 \\
\hline Low quality of leadership & 2.00 & 1.29 & 3.09 & 0.002 & 1.56 & 0.99 & 2.46 & 0.055 \\
\hline Low social support & 1.60 & 1.01 & 2.55 & 0.045 & 1.30 & 0.79 & 2.12 & 0.301 \\
\hline Low sense of community & 2.35 & 1.49 & 3.70 & $<0.001$ & 1.91 & 1.19 & 3.06 & 0.007 \\
\hline \multicolumn{9}{|l|}{ Work-individual interface } \\
\hline Low job satisfaction & 2.18 & 1.40 & 3.40 & 0.001 & 1.71 & 1.06 & 2.76 & 0.027 \\
\hline Work-family conflict & 1.62 & 1.08 & 2.43 & 0.021 & 1.44 & 0.90 & 2.31 & 0.130 \\
\hline High job insecurity & 2.78 & 1.88 & 4.12 & $<0.001$ & 2.25 & 1.44 & 3.50 & $<0.001$ \\
\hline High changes at work & 1.89 & 1.22 & 2.93 & 0.005 & 1.37 & 0.87 & 2.16 & 0.177 \\
\hline Temporary employment & 1.79 & 0.90 & 3.56 & 0.095 & 2.18 & 1.04 & 4.56 & 0.038 \\
\hline \multicolumn{9}{|l|}{ Workplace violence } \\
\hline High internal violence & 2.48 & 1.57 & 3.92 & $<0.001$ & 1.69 & 1.08 & 2.65 & 0.022 \\
\hline High external violence & 1.56 & 1.04 & 2.34 & 0.033 & 1.20 & 0.74 & 1.94 & 0.458 \\
\hline \multicolumn{9}{|l|}{ Working time/hours factors } \\
\hline Long working hours (> 48 h/week) & 0.74 & 0.44 & 1.24 & 0.249 & 0.76 & 0.42 & 1.38 & 0.371 \\
\hline Night work (> 50/year) & 1.00 & 0.53 & 1.89 & 0.998 & 0.83 & 0.40 & 1.69 & 0.599 \\
\hline Unsocial work days (> 40/year) & 0.88 & 0.54 & 1.43 & 0.594 & 0.61 & 0.37 & 1.02 & 0.061 \\
\hline Shift work & 1.19 & 0.64 & 2.24 & 0.584 & 1.28 & 0.62 & 2.66 & 0.504 \\
\hline \multicolumn{9}{|l|}{ Physical work exposures } \\
\hline High biomechanical exposure ${ }^{b}$ & 0.96 & 0.64 & 1.42 & 0.821 & 0.63 & 0.38 & 1.04 & 0.073 \\
\hline Fumes and dust exposure & 0.97 & 0.65 & 1.45 & 0.871 & 0.84 & 0.53 & 1.34 & 0.466 \\
\hline Toxic and dangerous products exposure & 0.93 & 0.62 & 1.38 & 0.707 & 0.81 & 0.55 & 1.22 & 0.317 \\
\hline Noise exposure & 1.22 & 0.79 & 1.88 & 0.381 & 1.08 & 0.69 & 1.69 & 0.731 \\
\hline
\end{tabular}

Odds-Ratio (OR) and 95\% confidence interval (Cl)

${ }^{\text {a }}$ Reported results are those from complete case analyses that included participants with no missing data for the variables of interest (suicide ideation, all occupational exposures, covariates). The observed associations were similar using all available data for each occupational exposure

${ }^{\mathrm{b}}$ Median cut-off of the total sample was used to classify workers in low or high exposure groups

'Adjusted for age, marital status, social support outside work, life events before the age of 18 , life events within the last 3 years, occupation, and economic activity of the company 
Table 3 Associations of occupational exposures with suicide ideation in women. Results from weighted logistic regression analyses (each occupational factor studied separately)

\begin{tabular}{|c|c|c|c|c|c|c|c|c|}
\hline \multirow{3}{*}{$\begin{array}{l}\text { Women }(N=10,666)^{a} \\
\text { Psychosocial work factors }^{b}\end{array}$} & \multicolumn{4}{|c|}{ Unadjusted } & \multicolumn{4}{|c|}{ Adjusted for covariates $^{c}$} \\
\hline & \multirow[t]{2}{*}{ OR } & \multicolumn{2}{|l|}{$95 \% \mathrm{Cl}$} & \multirow[t]{2}{*}{$p$-value } & \multirow[t]{2}{*}{ OR } & \multicolumn{2}{|c|}{$95 \% \mathrm{Cl}$} & \multirow[t]{2}{*}{$p$-value } \\
\hline & & & & & & & & \\
\hline \multicolumn{9}{|l|}{ Demands at work } \\
\hline High quantitative demands & 1.88 & 1.31 & 2.69 & 0.001 & 1.50 & 1.02 & 2.20 & 0.038 \\
\hline High cognitive demands & 1.97 & 1.35 & 2.86 & $<0.001$ & 1.74 & 1.18 & 2.59 & 0.006 \\
\hline High emotional demands & 1.71 & 1.11 & 2.63 & 0.014 & 1.41 & 0.87 & 2.28 & 0.165 \\
\hline High demands for hiding emotions & 2.33 & 1.45 & 3.72 & $<0.001$ & 1.44 & 0.89 & 2.34 & 0.134 \\
\hline \multicolumn{9}{|l|}{ Work organization and job content } \\
\hline Low influence & 1.49 & 1.06 & 2.10 & 0.023 & 1.47 & 1.03 & 2.09 & 0.034 \\
\hline Low degree of freedom & 1.54 & 1.06 & 2.23 & 0.025 & 1.36 & 0.93 & 1.97 & 0.109 \\
\hline Low possibilities for development & 1.39 & 0.96 & 2.00 & 0.080 & 1.12 & 0.77 & 1.62 & 0.548 \\
\hline Low meaning of work & 2.04 & 1.45 & 2.88 & $<0.001$ & 1.66 & 1.15 & 2.40 & 0.007 \\
\hline \multicolumn{9}{|l|}{ Interpersonal relations and leadership } \\
\hline Low predictability & 1.08 & 0.77 & 1.53 & 0.648 & 1.08 & 0.73 & 1.58 & 0.708 \\
\hline Low role clarity & 1.80 & 1.27 & 2.54 & 0.001 & 1.37 & 0.96 & 1.97 & 0.086 \\
\hline High role conflict & 2.54 & 1.77 & 3.63 & $<0.001$ & 1.79 & 1.23 & 2.61 & 0.002 \\
\hline Low quality of leadership & 1.87 & 1.30 & 2.71 & 0.001 & 1.37 & 0.94 & 1.98 & 0.102 \\
\hline Low social support & 2.05 & 1.37 & 3.06 & $<0.001$ & 1.42 & 0.95 & 2.14 & 0.089 \\
\hline Low sense of community & 2.07 & 1.39 & 3.09 & $<0.001$ & 1.44 & 0.97 & 2.14 & 0.067 \\
\hline \multicolumn{9}{|l|}{ Work-individual interface } \\
\hline Low job satisfaction & 1.89 & 1.32 & 2.70 & $<0.001$ & 1.26 & 0.85 & 1.87 & 0.242 \\
\hline Work-family conflict & 1.31 & 0.92 & 1.86 & 0.132 & 1.08 & 0.76 & 1.54 & 0.666 \\
\hline High job insecurity & 1.61 & 1.14 & 2.28 & 0.007 & 1.17 & 0.80 & 1.71 & 0.419 \\
\hline High changes at work & 2.37 & 1.64 & 3.43 & $<0.001$ & 1.50 & 1.01 & 2.25 & 0.046 \\
\hline Temporary employment & 1.06 & 0.59 & 1.92 & 0.839 & 1.02 & 0.53 & 1.97 & 0.953 \\
\hline \multicolumn{9}{|l|}{ Workplace violence } \\
\hline High internal violence & 3.02 & 1.99 & 4.59 & $<0.001$ & 2.11 & 1.38 & 3.23 & 0.001 \\
\hline High external violence & 1.64 & 1.16 & 2.32 & 0.005 & 1.42 & 0.99 & 2.02 & 0.056 \\
\hline \multicolumn{9}{|l|}{ Working time/hours factors } \\
\hline Long working hours (> 48 h/week) & 1.56 & 0.84 & 2.90 & 0.163 & 1.49 & 0.78 & 2.88 & 0.230 \\
\hline Night work (> 50/year) & 0.29 & 0.13 & 0.65 & 0.003 & 0.29 & 0.13 & 0.66 & 0.003 \\
\hline Unsocial work days (> 40/year) & 0.86 & 0.57 & 1.29 & 0.472 & 0.93 & 0.61 & 1.44 & 0.760 \\
\hline Shift work & 0.99 & 0.31 & 3.09 & 0.980 & 0.87 & 0.22 & 3.41 & 0.837 \\
\hline \multicolumn{9}{|l|}{ Physical work exposures } \\
\hline High biomechanical exposure ${ }^{b}$ & 1.39 & 0.98 & 1.97 & 0.062 & 1.15 & 0.77 & 1.72 & 0.498 \\
\hline Fumes and dust exposure & 1.29 & 0.90 & 1.85 & 0.169 & 1.02 & 0.66 & 1.55 & 0.940 \\
\hline Toxic and dangerous products exposure & 1.02 & 0.72 & 1.46 & 0.898 & 0.87 & 0.58 & 1.29 & 0.479 \\
\hline Noise exposure & 1.98 & 1.26 & 3.11 & 0.003 & 1.68 & 0.99 & 2.82 & 0.053 \\
\hline
\end{tabular}

Odds-Ratio (OR) and 95\% confidence interval (Cl)

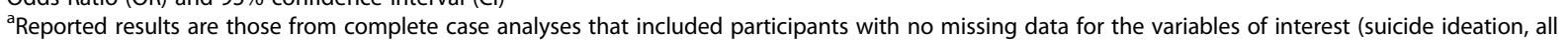
occupational exposures, covariates). The observed associations were similar using all available data for each occupational exposure

${ }^{b}$ Median cut-off of the total sample was used to classify workers in low or high exposure groups

${ }^{c}$ Adjusted for age, marital status, social support outside work, life events before the age of 18 , life events within the last 3 years, occupation, and economic activity of the company 
For both men and women, no exposure related to working time/hours and the physical work environment was associated with suicide ideation (Tables 2-3). Among women, night work was found to be a protective factor for suicide ideation, and noise exposure that was associated with suicide ideation before adjustment for covariates, was borderline significant after this adjustment.

Figures 1-2 show the results for multiple exposure in association with suicide ideation. Significant trend tests were observed for work organization and job content, interpersonal relations and leadership, and workindividual interface among men and for demands at work, interpersonal relations and leadership, and workplace violence among women. Trend tests for all psychosocial work factors together were significant for men and borderline significant among women. No interaction was found between gender and the number of psychosocial work factors in association with suicide ideation, suggesting no difference in linear trend between genders. No trend test was found to be significant for multiple exposure to working time/hours and physical work exposures (not showed).

\section{Discussion}

\section{Summary of the results}

The study is one of the first to provide a comprehensive view of the associations between occupational factors and suicide ideation. It showed that psychosocial work factors were associated with suicide ideation and that multiple exposure to these factors increased the risk of suicide ideation linearly. No factor related to working time/hours and the physical work environment was found to increase the risk of suicide ideation.

\section{Comparison with the literature}

The number of the previous studies on the associations between psychosocial work factors and suicide ideation is low. The literature reviews published recently showed that there were 14 studies that explored psychosocial work factors and suicide ideation [10] and 8 studies specifically on workplace bullying and suicide ideation [9]. Our results are in agreement with these reviews for job demands (quantitative and cognitive demands in our study), low job control (low influence, low possibilities for development), low social support (low sense of community), job insecurity, role conflict, and workplace bullying (internal violence). Our findings related to temporary employment are also in line with the results of two studies that showed that employment arrangement, in particular casual/fixed term employment, was associated with thoughts about suicide [13] and that precarious work was associated with suicidal ideation [14]. We found that low meaning at work and changes at work increased the risk of suicide ideation, results that have never been observed before. Our study showed that there was a linear association between multiple exposure to psychosocial work factors and suicide ideation, and

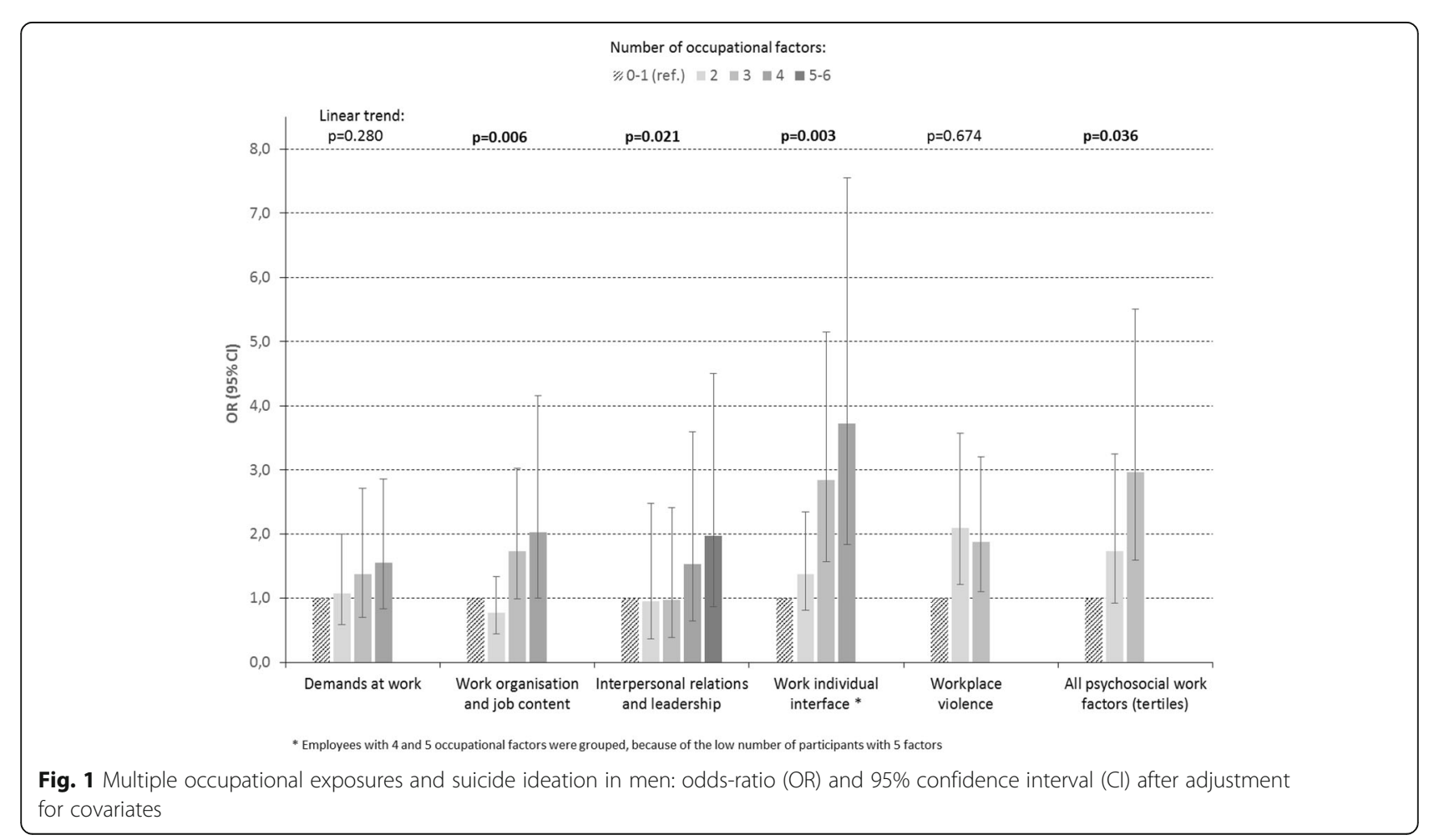




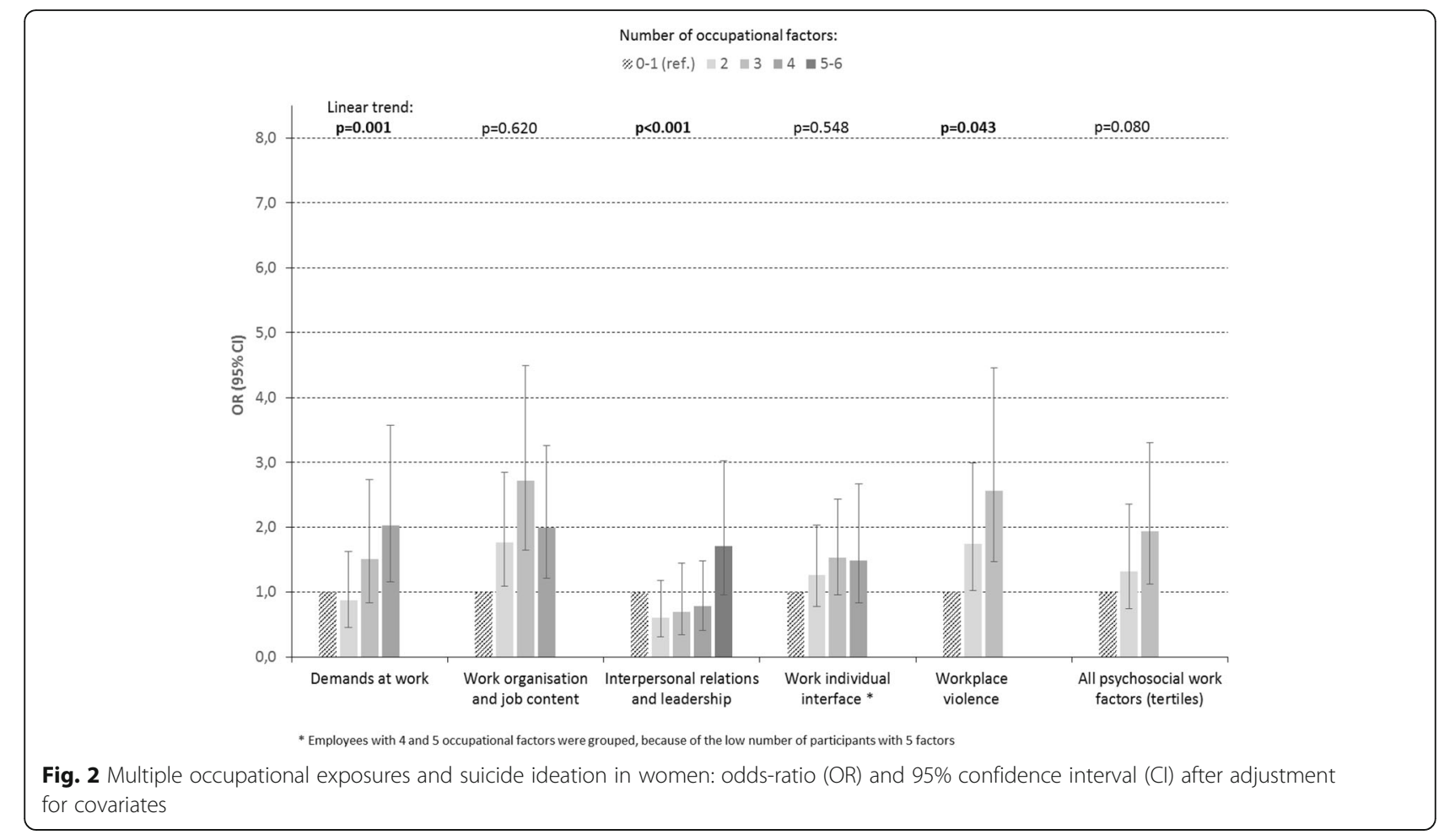

our study may be the first one to demonstrate the cumulative effects of these factors on suicide ideation. We found no association between exposures related to working time/hours and the physical work environment and suicide ideation. Other authors did not find any association between working time/hours and suicide ideation $[15,16]$. To our knowledge, information is missing on the associations between occupational exposures of physical nature and suicide ideation.

\section{Strengths and limitations of the study}

The study had many strengths. It was based on a large nationally representative sample of the working population with high participation and response rates. It used weights in order to provide results that could be extrapolated to the whole population. Men and women were studied separately and differences between genders including gender-related interactions were tested following the best practices $[17,18]$. We found that there were significant differences between genders in covariates and occupational exposures, in most cases, at the expense of women. Nevertheless, the prevalence of suicide ideation was not statistically different between men and women, and most of the exposure-outcome associations were similar between genders. There were, however, two exceptions for cognitive demands, observed as a risk factor among women only, and job insecurity, found as a risk factor among men only. This last association might be explained by the role of sole or main bread winner in the family taken by men. Suicide ideation was measured using one item already used in another national French survey (the Health Barometer), that found a similar 12month prevalence of suicide ideation $(3.9 \%$ in 2009 2010 in France) [11]. The study included a large number of occupational factors, especially psychosocial work factors. We also studied other occupational exposures related to working time/hours and physical exposures, that were not associated with suicide ideation. As our assumption was that psychosocial work factors would be more strongly associated with the outcome than the other occupational exposures, our results are thus consistent with what was expected. One of the major assets was the study of multiple exposures that has never been done before in association with suicide ideation. Important covariates were taken into account in the analyses and sensitivity analyses were performed that confirmed the robustness of the results.

The study had, however, some limitations. It was a cross-sectional study, consequently no causal conclusion could be drawn from the results and reverse causation was possible. A healthy worker effect might have selected the healthiest people at the workplace and at the most exposed jobs and led to an underestimation of the observed associations. This effect may be a potential explanation of the protective association between night work and suicide ideation found in our study. No validated questionnaire was used for the measurement of suicide ideation, and the item used did not include the 
frequency of thoughts. This single item may also have led to a recall bias. No validated questionnaire was used for the measurement of occupational factors, and some occupational factors may be missing such as organizational injustice. As the study relied on selfreported data, a reporting bias might be suspected that could lead to an overestimation of the associations. Some covariates may be missing such as history of mental disorders. Nevertheless, adjusting for mental disorders may lead to overadjustment, as these disorders, especially depression, are likely to be in the causal pathway between occupational exposures and suicide ideation. Indeed, depression is a major risk factor of suicidal behaviour and may thus explain the observed associations between psychosocial work factors and suicide ideation in our study.

\section{Conclusions}

Our study suggested that psychosocial work exposures may play a major role in suicide ideation, and the role of the other occupational exposures might be negligible in this outcome. Our results also showed that various psychosocial work factors were risk factors for suicide ideation, in particular those related to job demands, job control, interpersonal relationships including workplace violence, job insecurity, temporary employment, and changes at work. There were some rare differences in these risk factors between men and women. Finally, our study highlighted the cumulative role of psychosocial work factors in suicide ideation. More research is needed to confirm our results, and more prevention towards the psychosocial work environment may be useful to prevent suicide ideation among the working population. Our study may help and guide clinical practice to better identify the factors at the workplace that may increase the risk of suicide ideation. More attention should also be paid to the accumulation of these factors that may increase the risk still further.

\section{Acknowledgements}

The authors thank the members of DARES (French ministry of labour) and all the participants to the 2016 Working Conditions survey, who made this study possible.

\section{Authors' contributions}

IN conceived the study protocol, performed the literature review, and drafted and revised the manuscript. SB performed the statistical analysis. IN and JFC made contributions to the statistical analysis and interpretation of results. SB, JFC and MB made contributions to manuscript revisions. All authors read and approved the final manuscript.

\section{Funding}

The study was supported by DARES of the French ministry of labour (grant number: 2018/037). DARES had no role in study design; in the analysis and interpretation of data; in the writing of the manuscript; and in the decision to submit the manuscript for publication.

\section{Availability of data and materials}

The dataset used and analysed during the current study are available from the corresponding author on reasonable request.

\section{Ethics approval and consent to participate}

The survey was approved by French ethics committees (CNIL no 2015-079 and CNIS no 2015X073TV). All people who were included in the sample agreed to participate in the survey and signed the informed consent form.

\section{Consent for publication}

Not applicable.

\section{Competing interests}

The authors declare that they have no competing interests. Isabelle Niedhammer is a Section Editor for BMC Public Health but had no role in the editorial process.

\section{Author details}

${ }^{1}$ INSERM, Univ Angers, Univ Rennes, EHESP, Irset (Institut de recherche en santé, environnement et travail) - UMR_S 1085, ESTER Team, 28 rue Roger Amsler, CS 74521, 49045, Angers, France. ²DARES, Ministère du Travail, Paris, France.

Received: 24 January 2020 Accepted: 1 June 2020

Published online: 09 June 2020

References

1. Milner A, Morrell S, Lamontagne AD. Economically inactive, unemployed and employed suicides in Australia by age and sex over a 10-year period: what was the impact of the 2007 economic recession? Int J Epidemiol. 2014:43(5):1500-7.

2. Milner A, Spittal MJ, Pirkis J, Lamontagne AD. Suicide by occupation: systematic review and meta-analysis. Br J Psychiatry. 2013;203(6):409-16.

3. Niedhammer I, Milner A, Witt K, Klingelschmidt J, Khireddine-Medouni I, Alexopoulos EC, et al. Response to letter to the editor from Dr Rahman Shiri: the challenging topic of suicide across occupational groups. Scand J Work Environ Health. 2018:44(1):108-10.

4. Bonde JP. Psychosocial factors at work and risk of depression: a systematic review of the epidemiological evidence. Occup Environ Med. 2008:65(7): 438-45.

5. Madsen IEH, Nyberg ST, Magnusson Hanson LL, Ferrie JE, Ahola K, Alfredsson $L$, et al. Job strain as a risk factor for clinical depression: systematic review and meta-analysis with additional individual participant data. Psychol Med. 2017:47(8):1342-56.

6. Netterstrom B, Conrad N, Bech P, Fink P, Olsen O, Rugulies R, et al. The relation between work-related psychosocial factors and the development of depression. Epidemiol Rev. 2008;30:118-32.

7. Stansfeld S, Candy B. Psychosocial work environment and mental health--a meta-analytic review. Scand J Work Environ Health. 2006;32(6):443-62.

8. Theorell T, Hammarstrom A, Aronsson G, Traskman Bendz L, Grape T, Hogstedt C, et al. A systematic review including meta-analysis of work environment and depressive symptoms. BMC Public Health. 2015:15:738,

9. Leach LS, Poyser C, Butterworth P. Workplace bullying and the association with suicidal ideation/thoughts and behaviour: a systematic review. Occup Environ Med. 2017:74(1):72-9.

10. Milner A, Witt K, LaMontagne AD, Niedhammer I. Psychosocial job stressors and suicidality: a meta-analysis and systematic review. Occup Environ Med. 2018;75(4):245-53

11. Husky MM, Guignard R, Beck F, Michel G. Risk behaviors, suicidal ideation and suicide attempts in a nationally representative French sample. J Affect Disord. 2013;151(3):1059-65.

12. Doyal L. Sex and gender: the challenges for epidemiologists. Int J Health Serv. 2003:33(3):569-79.

13. Milner A, LaMontagne AD, Spittal MJ, Pirkis J, Currier D. Job stressors and employment Precarity as risks for thoughts about suicide: an Australian study using the ten to men cohort. Ann Work Expo Health. 2018;62(5):58390.

14. Min KB, Park SG, Hwang SH, Min JY. Precarious employment and the risk of suicidal ideation and suicide attempts. Prev Med. 2015;71:72-6.

15. Takusari E, Suzuki M, Nakamura H, Otsuka K. Mental health, suicidal ideation, and related factors among workers from medium-sized business 
establishments in northern Japan: comparative study of sex differences. Ind Health. 2011;49(4):452-63.

16. Tyssen R, Vaglum P, Gronvold NT, Ekeberg O. Suicidal ideation among medical students and young physicians: a nationwide and prospective study of prevalence and predictors. J Affect Disord. 2001;64(1):69-79.

17. Niedhammer I, Saurel-Cubizolles MJ, Piciotti M, Bonenfant S. How is sex considered in recent epidemiological publications on occupational risks? Occup Environ Med. 2000;57(8):521-7.

18. Quinn MM, Smith PM. Gender, work, and health. Ann Work Expo Health. 2018;62(4):389-92.

\section{Publisher's Note}

Springer Nature remains neutral with regard to jurisdictional claims in published maps and institutional affiliations.

Ready to submit your research? Choose BMC and benefit from:

- fast, convenient online submission

- thorough peer review by experienced researchers in your field

- rapid publication on acceptance

- support for research data, including large and complex data types

- gold Open Access which fosters wider collaboration and increased citations

- maximum visibility for your research: over $100 \mathrm{M}$ website views per year

At BMC, research is always in progress.

Learn more biomedcentral.com/submissions 